\title{
THE ALGORITHM FOR DETERMINATION OF NECESSARY CHARACTERISTICS OF BACKFILL MATERIALS USED FOR GROUNDING RESISTANCES OF GROUNDING LOOPS REDUCTION
}

\author{
Jovan Trifunović ${ }^{*}$
}

\begin{abstract}
Various backfill materials are used with the aim to reduce grounding resistance of grounding systems to the desired values. The algorithm for determination of a proper combination of features a backfill material needs to possess in order to successfully perform this task is developed and presented. It is based on the numerical analysis of the results obtained with finite-element method modelling of the considered grounding system, surrounding soil, backfill material and imperfect contact. As an example, the developed algorithm is applied on two grounding loops (one conventional and the other backfilled with bentonite suspension) embedded in a two-layer soil. The results obtained with the application of the proposed algorithm can be used as guidance for the researchers who are looking for new suitable low cost backfill materials.
\end{abstract}

Keywords: grounding loop, grounding resistance, backfill material, imperfect contact, contact resistance, finiteelement method

\section{INTRODUCTION}

Grounding grids are the elements of electric power systems, the quality of which most significantly influences safety and reliability of the system operation. One of the most important parameters of the grid is grounding resistance. Many papers proposed simple methods and formulas for calculations of the grounding resistances of various grids shapes, buried in various soil structures [1-10]. All of those methods and formulas were derived starting from the Laplace solution to the problem, assuming ideal contact surface between the grounding grid electrodes and the surrounding soil. However, it was noticed in practice [11] that such formulas could not give accurate calculation results of the grid grounding resistance in soils where the significant part of the electrode surface is actually not in contact with the surrounding soil (eg karst and sandy terrains). In such cases, due to the contact resistance, the values of measured grounding resistances are usually several times higher than the values obtained with calculation. In order to reduce the values of grounding resistance to values less than or equal to ones calculated using the standard engineering methods, different backfill materials are used in practice [11-21].

It is important to choose the backfill material which will successfully eliminate the component of contact resistance from the total grounding resistance. In recent years, bentonite has proven to be the best backfill material for this purpose [11-14]. However, such a backfill material is comparatively expensive because in most developing countries it often has to be imported [15]. Therefore, to reduce the cost, it is necessary to find local low cost alternative backfill materials which can be used as close substitutes for bentonite. In order to find such materials, many studies were carried out including various materials:

- waste drilling mud [11],

- palm kernel oil cage, tyre ash, wood ash and powdered cocoa shells [16],

- coconut coir peat, planting-clay soil and paddy dust $[15,17]$,

- granulated blast furnace slag [18],

- fly ash [19], etc.

There are two different opinions about what is the most important necessary characteristic of a backfill material, which actually provides the elimination of the undesired contact resistance component — some authors believe that it is the ability of backfill material to enhance the quality of physical contact achieved between the grounding electrodes and the surrounding soil $[11,12]$, while the others believe that it is the low electrical resistivity of backfill material [17-21]. However, the research presented in this paper shows that value of grounding resistance in karst and sandy terrains could be significantly decreased by usage of a backfill material which is either characterised by low resistivity or by ability to provide excellent contact with the grounding electrodes, or by proper combination of those two characteristics. The algorithm for determination of a proper combination of those two features which backfill material needs to possess in order to provide the decrease of the grounding resistance of a loop to the desired values is developed and presented. It is based on the numerical analysis of the results obtained with finite-element method (FEM) [22-24] modelling of the considered grounding grid, surrounding

* Faculty of Electrical Engineering, University of Belgrade, Bulevar kralja Aleksandra 73, 11000 Belgrade, Serbia, jovan.trifunovic@etf.rs 


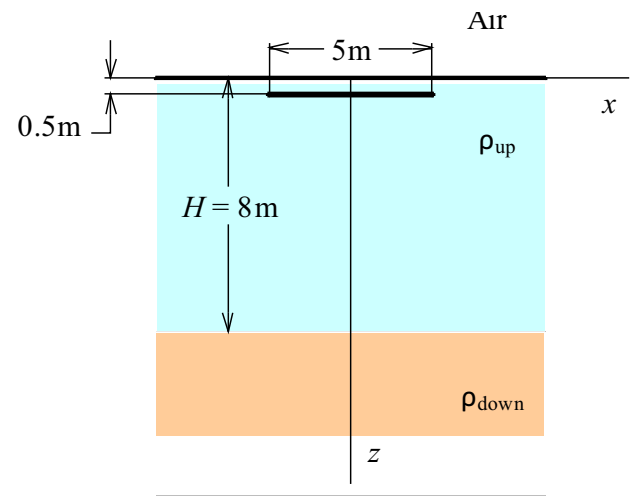

Fig. 1. The grounding loop buried in a two-layer soil

soil, backfill material and imperfect contact. The results obtained with the application of such algorithm can be used as guidance for the researchers who are looking for new suitable low cost backfill materials. In this paper, as an example, the developed algorithm is applied on two grounding loops (one conventional and the other backfilled with bentonite suspension) embedded in a two-layer soil.

\section{THE ALGORITHM FOR DETERMINATION OF THE NECESSARY COMBINATION OF FEATURES FOR THE BACKFILL MATERIAL}

The most desired feature of a backfill material is the ability to successfully reduce values of grounding resistances of grounding grids $(R)$ to ones calculated using the standard engineering methods assuming ideal contact surface between the grounding grid electrodes and the surrounding soil $\left(R_{0}\right)$. Two characteristics of backfill material which are essential for this purpose are its resistivity $\left(\rho_{b f}\right)$ and contact quality achieved with the grounding electrodes. The latter can quantitatively be described by the parameter that represents fraction of the grounding grid surface which, in reality, is not achieving contact with the surrounding soil $(F)$. The only way to determine pairs of values $\left(\rho_{b f}, F\right)$ the backfill material needs to possess, in order to successfully reduce the values of grounding resistance to desired values, is to find the analytical expression for the dependence $R\left(\rho_{b f}, F\right)$ and then find pairs of values $\left(\rho_{b f}, F\right)$ that satisfy the condition

$$
R\left(\rho_{b f}, F\right) \leq R_{0} .
$$

Practically, it would be very hard, or even impossible, to analytically derive the expression $R\left(\rho_{b f}, F\right)$ using the standard electromagnetic theory. The reason is geometry of the problem, which becomes very complex due to addition of subdomain with backfill material which surrounds the grounding grid and modelling of imperfect contact by air gaps placed between the grounding loop electrodes and the surrounding soil. However, the expression $R\left(\rho_{b f}, F\right)$ can be derived by performing the numerical analysis of grounding resistances values obtained with FEM modelling. This method possesses an advantage of

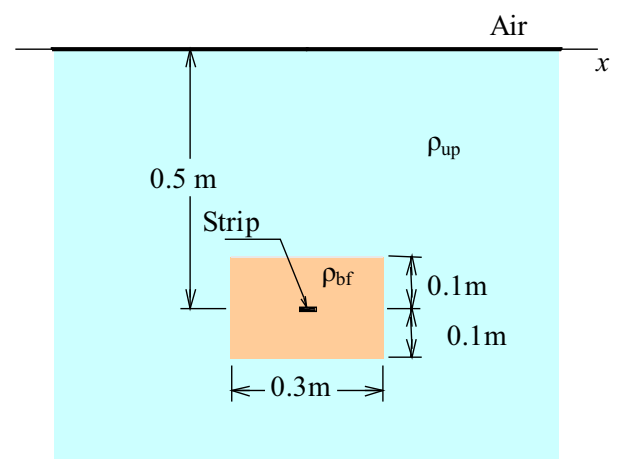

Fig. 2. Installation of a grounding strip surrounded by backfill material

being independent from shape and size of the grid, as well as the soil structure, allowing the fast 3-D problem modelling with taking soil irregularities, such as air gaps and/or backfill materials characterised by various electrical resistivity and sizes, in consideration.

To summarise, the proposed algorithm is composed of the following 4 steps:

1. FEM modelling of the considered grounding grid, surrounding soil, backfill material and imperfect contact (air gaps),

2. Using the FEM model to calculate the grounding resistances of the considered grounding grid for backfill material characterised by several different pairs of values $\left(\rho_{b f}, F\right)$,

3. Performing the numerical analysis of grounding resistances values obtained with FEM, in order to derive the expression $R\left(\rho_{b f}, F\right)$, and

4. Finding the pairs of values $\left(\rho_{b f}, F\right)$ that satisfy the condition expressed by (1).

As an example, the developed algorithm is applied on grounding loops embedded in a two-layer soil (loop is the simplest form of a grid), the experimental results of which were reported in [11].

\section{APPLICATION OF THE PROPOSED ALGORITHM ON REAL GROUNDING LOOPS}

\subsection{Step 1: FEM modelling of grounding loops}

As reported in [11], the two identical grounding loops, made of zinc protected steel strips with rectangular cross-section $(30 \mathrm{~mm} \times 4 \mathrm{~mm})$ were installed in a former stonebed. The structure of soil was described as a twolayer composition $\left(\rho_{\text {up }}=170 \Omega \mathrm{m}, \rho_{\text {down }}=75 \Omega \mathrm{m}\right.$ and $H=8 \mathrm{~m}$ (Fig. 1)), where the upper soil layer was made of stones (karst terrain). Dimensions of the grounding loops $(5 \mathrm{~m} \times 5 \mathrm{~m})$ belong to the range of dimensions of grounding loops used in transformer stations $10 \mathrm{kV} / 0.4 \mathrm{kV}$, as well as of loops used as parts of a grounding system of $35 \mathrm{kV}$ transmission line towers. The loops were installed at a depth of $0.5 \mathrm{~m}$ (Fig. 1).

The backfill material for the first loop channel was excavated material. The second loop channel was backfilled 

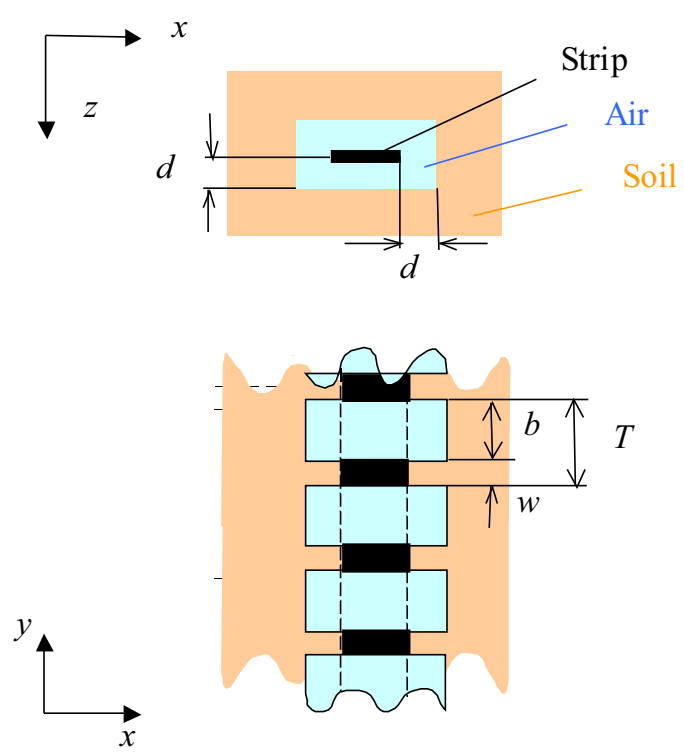

Fig. 3. Schematic representation of the concept of placing air gaps along the grounding strip

with $1200 \mathrm{l}$ of bentonite suspension and the rest of the channel was filled with the excavated material. The installation of the grounding loop backfilled with the bentonite suspension is shown in Fig. 2. Resistivity of this backfill material was $\rho_{b f}=\rho_{\text {bentonite }}=2.5 \Omega \mathrm{m}$.

The described experimental setup was modelled applying FEM similarly as in [25-27], with addition of subdomain with backfill material which surrounds the grounding grid and modelling of imperfect contact by air gaps placed between the grounding loop electrodes and the surrounding soil.

The dimensions of the initial cube model were $20 \mathrm{~m} \times$ $20 \mathrm{~m} \times 20 \mathrm{~m}$. Each side of this cube, except for the upper side representing the boundary between the soil and air, was surrounded by additional $2 \mathrm{~m}$ thick walls (subdomains) made of boundary infinite elements [28]. The electric potential of outer surfaces of these walls was set on $0 \mathrm{~V}$ (distant ground). The grounding loop, located at a depth of $0.5 \mathrm{~m}$ and in the middle of the cube cross-section, was modelled as a subdomain with its realistic dimensions and electrical properties. The subdomain with backfill material which surrounds the grounding loop was also added (dimensions of the additional subdomains crosssection are shown in Fig. 2). The properties of each soil layer were defined by means of the electrical conductivity. Air gaps were placed sequentially along the grounding loop perimeter, preventing any contact between the strip and the surrounding soil over the whole surface of the sequence completely surrounded by the air gap (the cross-section in $x z$ plane of the modelled air gap surrounding a strip sequence, as well as a part of the strip in xy plane showing the sequential distribution of air gaps, are presented in Fig. 3 ( $b$ represents the length of the strip sequence completely surrounded by the air gap, $w$ the length of the strip sequence along which the perfect contact exists between its surface and the surrounding soil, and $d$ the thickens of the air gap).

The quality of contact achieved between the grounding electrodes and the surrounding soil is quantitatively described by the parameter that represents the fraction of the grounding electrodes surface which, in reality, is not achieving the contact with the surrounding soil $(F)$. This parameter can be calculated as

$$
F(\%)=\frac{b}{T} \times 100=\frac{b}{b+w} \times 100 .
$$

where $T$ is determined by

$$
T=\frac{P}{n}
$$

( $P$ is the grounding loop perimeter $(20 \mathrm{~m}$ in the considered case) and $n$ the number of air gaps along the whole loop).

The finite-element mesh in the model volume was made by four-node solid elements (tetrahedrons). Due to the symmetry, the initial model could be divided vertically in eight identical parts. Hence, the final model comprised only one eight of the initial model.

The potentials of all finite-element nodes, as well as the current density at arbitrary location of the model volume, can be calculated by FEM software. This makes it possible to determine the total current dissipating from the grounding loop, as well as the loop grounding resistance (simply by dividing the electric potential applied on the grounding loop $(200 \mathrm{~V})$ by the determined current). The number of tetrahedral finite elements used in this analysis ranged from 100000 to 240000 , providing high accuracy of the results. The very small elements are used around the strip, increasing in size as they get further away from the strip.

Values of backfill material resistivity (for the fixed volume of $1200 \mathrm{l}$ in the considered case), as well as of parameter $F$ (for the fixed values of $d=16 \times 10^{-3} \mathrm{~m}$ and $n=80$ ), were varied and their influences on the grounding loop resistance were analysed.

\subsection{Step 2: Calculating the grounding resis- tances for several different pairs of values $\left(\rho_{b f}, F\right)$}

First the values of parameter $F$ were varied (for several fixed values of backfill material resistivity), and the grounding resistances of the described grounding loop were calculated using FEM. Then the values of backfill material resistivity (for several fixed values of parameter $F$ ) were varied and the grounding resistances of the described grounding loop were calculated using FEM. Some results of these calculations are graphically presented in Figs. 4 and 5, respectively.

In the considered case the grounding resistance of conventional loop, calculated by FEM, amounted to $R_{0}=$ $14.85 \Omega$ (the value which corresponds to the ones calculated using the standard engineering methods). It is obvious from the curves shown in Fig. 4 that the values 


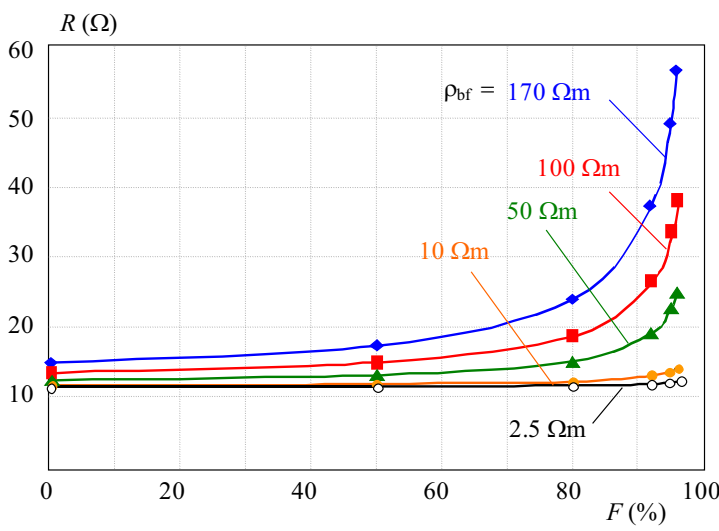

Fig. 4. Dependences of grounding resistances of the described grounding loop from parameter $F$, for several fixed values of backfill material resistivity, calculated using FEM

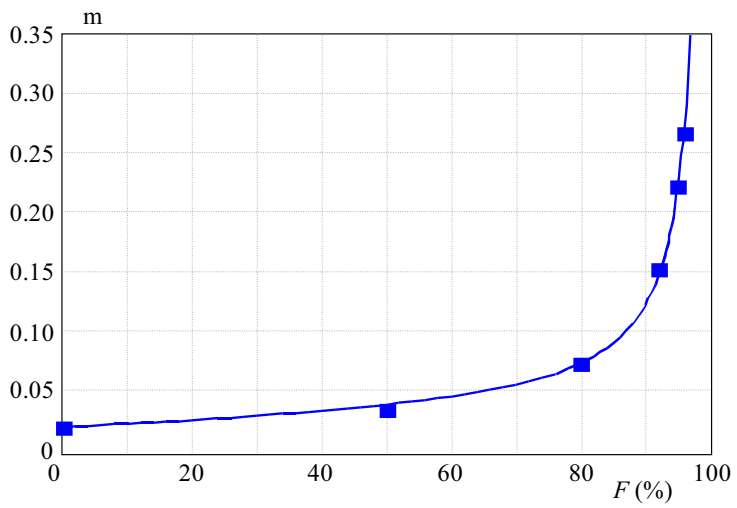

Fig. 6. The curve $m(F)$, fitted through the several values of slopes of lines representing $R\left(\rho_{b f}\right)$ dependences of the described grounding loop

of grounding resistance less than or equal to the basic value $R_{0}$ can be obtained with backfill materials characterised by different electrical resistivities, but with constraint that with increase of its resistivity the quality of contact achieved between backfill material and grounding electrodes (quantitatively described through the value of parameter $F$ ) must be sufficiently high ie the value of parameter $F$ must be sufficiently low.

Note that the measured value of grounding resistance of considered conventional loop reported in [11] was $R=$ $50.2 \Omega$. As noticed in [11], the big difference between the measured and computed grounding resistances was caused by a bad contact between the grounding electrodes and the surrounding soil. By examining the curve for $\rho_{b f}=\rho_{\text {up }}=170 \Omega \mathrm{m}$ shown in Fig. 4, it could be concluded that the upper soil layer was characterized by $F=95.19 \%$.

As for the loop backfilled with bentonite suspension, there is a very good correlation between the experimentally obtained value reported in [11] $(R=12.5 \Omega)$ and the one calculated by using the FEM $(R=11.5 \Omega)$. The existence of a small difference between the measured and calculated value can probably be attributed to the following two possibilities:

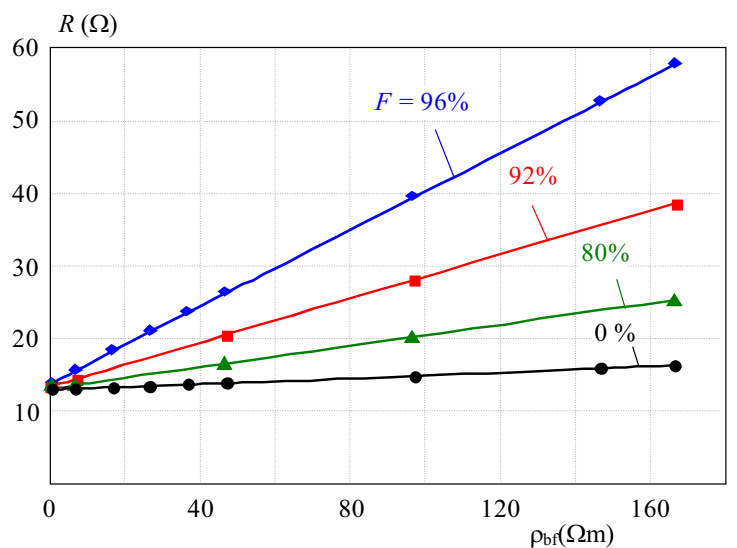

Fig. 5. Dependences of grounding resistances of the described grounding loop from the backfill material resistivity, for several fixed values of parameter $F$, calculated using FEM

1. the distribution of backfill material around the grounding loop electrodes was not uniform along the whole perimeter of the loop and deviated from the one presented in Fig. 2, and

2. the structure of the real soil was more complex than the two-layer structure which was used for the model creation.

\subsection{Step 3: Numerical analysis of the values of grounding resistances obtained with FEM}

In order to derive the expression $R\left(\rho_{b f}, F\right)$ for the considered case, the numerical analysis of the values of grounding resistances obtained with FEM has to be performed.

It is obvious from the diagram shown in Fig. 5 that the grounding resistance of the described grounding loop is, for fixed value of parameter $F$, almost perfectly linearly dependent on the backfill material resistivity. This dependency can be approximated by following basic linear equation

$$
R\left(\rho_{b f}\right)=m \rho_{b f}+c,
$$

where parameter $m$ represents the slope or gradient of the line and the constant $c$ determines a point at which the line crosses the $R$-axis. Here, the constant $c$ physically represents grounding resistance value when backfill material is an ideal conductor $i e$ the loop conductors cross-section is increased to the outer borders of backfill material shown in Fig. 2. In this case the grounding resistance obtained with FEM amounted to $c=11.43 \Omega$. It is also obvious from the diagram shown in Fig. 5 that the value of parameter $F$ does not influence the value of constant $c$, but it significantly influences the value of parameter $m$.

In order to determine the expression by which the parameter $m$ can be approximated as a function of $F$, first the fitting of the straight lines (4), for several fixed values of parameter $F$, through the points $\left(R, \rho_{b f}\right)$ calculated using FEM was performed using the method of least squares and the iterative calculation method. The values 


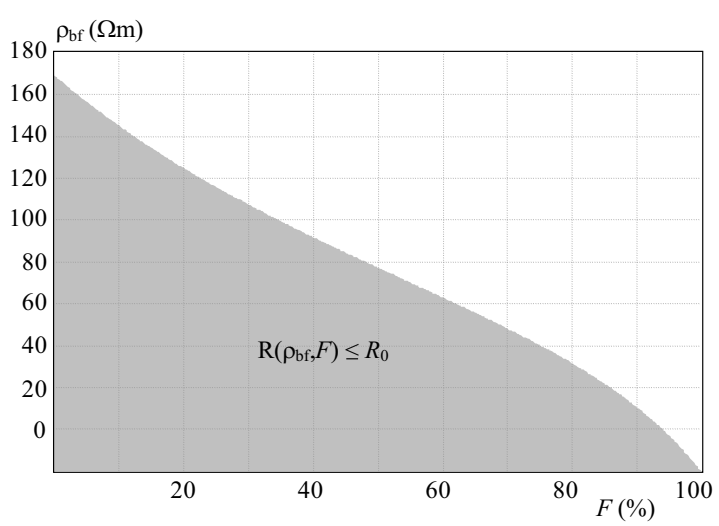

Fig. 7. The pairs of values $\left(\rho_{b f}, F\right)$ a backfill material need to possess in order to successfully reduce the values of grounding resistance to ones calculated using the standard engineering methods

of parameter $m$, obtained in such manner for several different values of parameter $F$, are presented at the diagram shown in Fig. 6 as points marked by black squares.

By examining those values, it was noticed that the parameter $m$, as a function of $F$, in the analysed case can be approximated by the following expression

$$
m(F)=C_{1}+C_{2} F+\frac{C_{3}}{100-F}
$$

where $C_{1}, C_{2}$ and $C_{3}$ are the constant coefficients. Incorporating (5) into (4), the latter becomes

$$
R\left(\rho_{b f}, F\right)=\left(C_{1}+C_{2} F+\frac{C_{3}}{100-F}\right) \rho_{b f}+c .
$$

By using the method of least squares and the iterative calculation method, constraining the values of point $\left(R_{0}\right.$, $\left.\rho_{b f}, F\right)$ which are gained by $(6)$ to its initial values of $(14.85,170,0)$, the following coefficients $C_{1}, C_{2}$ and $C_{3}$ are determined for the considered case

$$
\left(C_{1}, C_{2}, C_{3}\right)=(0.010491,0.000187,0.962692) .
$$

The curve $m(F)$ for the considered case, plotted using (5) with the incorporated determined coefficients $C_{1}, C_{2}$ and $C_{3}$, is also shown in Fig. 6. It is obvious that the excellent compliance is provided between the (5) and several values of parameter $\mathrm{m}$ obtained with earlier calculations. By examining the (6) it can be concluded that coefficient $C_{3}$ depends on the geometry of backfill material in region with air gaps (near the grounding electrodes), coefficient $C_{1}$ depends on the geometry of backfill material between the region of air gaps and outer borders of backfill material, while coefficient $C_{2}$ depends on the geometry of region which represents the border between previous two regions.

Note that the derived dependence $R\left(\rho_{b f}, F\right)$ expressed by (6), as well as the determined coefficients $C_{1}, C_{2}, C_{3}$ and $c$, are valid only for input parameters given in Section 3.1. For any other grounding system, characterised by different shape and size, soil structure (number and depths of layers and their resistivities) and soil irregularities (such as air gaps and/or backfill materials characterised by various volumes and distributions), first three steps of the proposed algorithm have to be conducted with its input parameters in order to derive the dependence $R\left(\rho_{b f}, F\right)$ and determine coefficients. However, it is possible that the dependence $R\left(\rho_{b f}, F\right)$ expressed by (6) will be general for the largest number of standard cases that can be found in practice.

\subsection{Step 4: Finding the pairs of values $\left(\rho_{b f}, F\right)$ that satisfy the condition expressed by (1)}

The pairs of values $\left(\rho_{b f}, F\right)$ that satisfy the condition expressed by (1) can be determined by incorporating (6) into (1),

$$
R_{0} \geq\left(C_{1}+C_{2} F+\frac{C_{3}}{100-F}\right) \rho_{b f}+c,
$$

and by rearranging (7), which then becomes

$$
\rho_{b f} \leq \frac{R_{0}-c}{C_{1}+C_{2} F+\frac{C_{3}}{100-F}} .
$$

By introducing all of the coefficients determined for the considered case into (8), it becomes

$$
\rho_{b f} \leq \frac{14.85-11.43}{0.010491+0.000187 F+\frac{0.962692}{100-F}} .
$$

The shaded area shown in Fig. 7, drawn using (9), represents the area in which every pair of values $\left(\rho_{b f}, F\right)$ satisfy the condition expressed by (1) for the considered case. This means that, in the considered case, any backfill material characterised by pairs of values $\left(\rho_{b f}, F\right)$ located in the hatched area shown in Fig. 7 will successfully reduce the values of grounding resistance to ones calculated using the standard engineering methods, eliminating the component of contact resistance from the total grounding resistance.

The algorithm can also be used for determining pairs of values $\left(\rho_{b f}, F\right)$ which backfill material needs to possess in order to successfully reduce the value of grounding resistance to any other desired or demanded value, as well. In that case, the value of $R_{0}$ from (1) should be replaced by the desired value of grounding resistance, and the Step 4 of the algorithm should be repeated.

\section{DISCUSSION}

By examining data given in Fig. 7, it can be concluded that the value of grounding resistance in karst and sandy terrains could be significantly decreased by using a backfill material which is either characterised by low resistivity or by ability to provide excellent contact with the grounding electrodes, or by proper combination of those two characteristics. The bentonite suspension, which was used as the backfill material in the described experiment, 
has both features - it is characterised by low resistivity $(\sim 2.5 \Omega \mathrm{m})$ and it provides the excellent contact with the grounding electrodes due to ability to adhere to nearly any surface it touches, and it can therefore be considered as the perfect backfill material for grounding systems. However, the results of conducted analyses indicate that, if bentonite is not available at the site, other materials, characterised by proper combination of features, can sufficiently decrease the grounding resistance if used as backfill materials.

The algorithm presented above can be used for choosing a backfill material which can successfully reduce the values of grounding resistance to any desired or demanded value. However, although the information on electrical resistivity of potential backfill materials can easily be found in literature or measured, the parameter $F$, which is used to quantitatively describe the quality of contact achieved between a backfill material and the grounding electrodes, is neither available in literature nor it is easily measurable. Nevertheless, this parameter can be determined experimentally, analysing the measured results and comparing it with the results obtained with FEM modelling. The authors present attempts are focused on simplifying the method for obtaining the information which quantitatively describes the quality of contact achieved between a backfill material and the grounding electrodes. Another concern to be addressed is the influence of backfill material on the ground surface potential distribution during the earth fault, because it is possible that the values of touch and step voltages in case of backfill material use will significantly differ from ones calculated using the standard engineering methods, even if the grounding resistance is decreased to the desired values.

\section{CONCLUSIONS}

The algorithm for determination of the proper combination a backfill material has to be characterised by, in order to provide the decrease of the grounding resistance of a loop to the desired values, is developed and presented. It is based on the numerical analysis of the results obtained with finite-element method modelling of the considered grounding loop, surrounding soil, backfill material and imperfect contact. This approach is adopted because it possesses an advantage of being independent from shape and size of the grid, as well as the soil structure, allowing the fast 3-D problem modelling, with taking soil irregularities, such as air gaps and/or backfill materials characterised by various electrical resistivities and sizes, in consideration.

As an example, the developed algorithm is applied on two grounding loops (one conventional and the other backfilled with bentonite suspension) embedded in a twolayer soil. Analyzing the influences of electrical resistivity of backfill material, as well as of quality of contact achieved between backfill material and grounding electrodes, on the loop grounding resistance, it is concluded that the value of grounding resistance in karst and sandy terrains could be significantly decreased by usage of a backfill material which is either characterised by low resistivity or by ability to provide excellent contact with the grounding electrodes, or by proper combination of those two characteristics. The results obtained with the application of the developed algorithm can be used as guidance for the researchers who are looking for new suitable low cost backfill materials.

\section{Acknowledgement}

This research was partially supported by the Ministry of Education and Science of Serbia (project TR 36018).

\section{REFERENCES}

[1] Guide for Safety in AC Substation Grounding, ANSI/IEEE Std. 80, 1986.

[2] Guide for Safety in AC Substation Grounding, ANSI/IEEE Std. 80, 2000.

[3] BRANDENBURSKY, V.-FARBER, A.-KORJ, V.BRAUNSHTEIN, A.: Ground Resistance Calculation for Small Concrete Foundations, Electr. Pow. Syst. Res. 81 (2011),408-413.

[4] SAlAma, M. M. A.-ElSherbiny, M. M.-CHOW, Y. L.-KIM, K. C.: Calculation and Interpretation of a Grounding Grid in Two-Layer Earth with the Synthetic-Asymptote Approach, Electr. Pow. Syst. Res. 35 (1995), 157-165.

[5] MOMBELLO, E.-TRAD, O.-RIVERA, J.-ANDREONI, A.: Two-Layer Soil Model for Power Station Grounding System Calculation Considering Multilayer Soil Stratification, Electr. Pow. Syst. Res. 37 (1996), 67-78.

[6] KOSTIC, M. B.: Analysis of Foundation Grounding Systems with External Loops and Rods, IEE Proc C 140 (1993), 73-76.

[7] KOSTIC, M. B. : Parametric Analysis of Foundation Grounding Systems Surrounded by Two-Layer Soil, IEEE T. Power Deliver 9 (1994), 1406-1411.

[8] KOSTIC, M. B. : Analysis of Complex Grounding Systems Consisting of Foundation Grounding Systems with External Grids, IEEE T. Power Deliver 13 (1998), 752-756.

[9] NAHMAN, J.-SKULETIC, S.: Resistances to Ground and Mesh Voltages of Ground Grids, Proc. IEE 126 (1979), 57-61.

10] CHOW, Y. L.-ELSHABINY, M. M.-SAlAMA, M. M. A. : A fast and Accurate Analysis of Grounding Resistance of a Driven Rodbed in a Two-Layer Soil, IEEE T. Power Deliver. 11 (1996), 808-814.

11] KOSTIC, M. B.-RADAKOVIC, Z. R.-RADOVANOVIC, N. S. TOMASEVIC-CANOVIC, M. R. : Improvement of Electrical Properties of Grounding Loops by using Bentonite and Waste Drilling Mud, IEE P. Gener.Transm. D. 146 (1999), 1-6.

[12] JONES, W. R.: Bentonite Rods Assure Ground Rod Installation in Problem Soils, IEEE T. Power Ap. Syst. PAS-99 (1980), 1343-1346.

[13] RADAKOVIC, Z. R.-KOSTIC, M. B. : Behaviour of Grounding Loop with Bentonite During a Ground Fault at an Overhead Line Tower, IEE P. Gener. Transm. D. 148 (2001), 275-278.

[14] KUTTER, H.-LANGE, W. : Grounding Improvement by using Bentonite, Elektrie 21 (1967), 421-424.

[15] JASNI, J.-SIOW,-Ab KADIR, M. Z. A.-Wan AHMAD, W. F. : Natural Materials as Grounding Filler for Lightning Protection System, $30^{\text {th }}$ International Conference on Lightning Protection - ICLP 2010, Cagliari, Italy, September 13-17, 2010.

[16] EDUful, G. COLE, J. E.-OKYERE, P. Y.: Optimum Mix of Ground Electrodes and Conductive Backfills to Achieve a 
Low Ground Resistance, $2^{\text {nd }}$ International Conference on Adaptive Science \& Technology, Accra, Ghana, 14-16 Jan 2009, pp. 140-145.

[17] KUMARASINGHE, N.: A Low Cost Lightning Protection System and its Effectiveness, $20^{\text {th }}$ International Lightning Detection Conference, Tucson, Arizona, April 2008.

[18] CHEN, L. H.-CHEN, J. F.-LIANG, T. J.-WANG, W. I. : A Study of Grounding Resistance Reduction Agent using Granulated Blast Furnace Slag, IEEE T. Power Deliver 19 (2004), 973-978.

[19] CHEN, L. H.-CHENG, C. K.-CHEN, J. F. : An Experimental Study on the Electrical Properties of Fly Ash in the Grounding System, International Journal of Emerging Electric Power Systems 7 No. 2 (2006)), Article 7.

[20] CHEN, L. H.-CHEN, J. F.-LIANG, T. J.-WANG, W. I. : A Research on used Quantity of Ground Resistance Reduction Agent for Ground Systems, European Transactions on Electrical Power 20 (2010), 408-421.

[21] Al-ARAinY, A. A.-MALIK, N. H.-QURESHI, M. I.KHAN, Y.: Grounding Pit Optimization using Low Resistivity Materials for Applications in High Resistivity Soils, International Journal of Emerging Electric Power Systems 12 No. 1 (2011), Article 3.

[22] JIN, J.: The Finite Element Method in Electromagnetics, John Wiley \& Sons, New York, 2002.

[23] ZIENKIEWICZ, O. C.-TAYLORR. L.-ZHU, J. Z.: The Finite Element Method: Its Basis and Fundamentals, Elsevier, Butterworth-Heinemann, Oxford, 2005.
[24] SILVESTER, P. P.-FERRARI, R. L.: Finite Elements for Electrical Engineers, Cambridge University Press, 1996.

[25] NAHMAN, J.-PAUNOVIC, I. : Resistance to Earth of Earthing Grids Buried in Multi-Layer Soil, Electr. Eng. 88 (2006), 281-287.

[26] NAHMAN, J.-PAUNOVIC, I.: Effects of the Local Soil Nonuniformity upon Performances of Ground Grids, IEEE T. Power Deliver 22 (2007), 2180-2184.

[27] NAHMAN, J.-PAUNOVIC, I.: Mesh voltages at Earthing Grids Buried in Multi-Layer Soil, Electr. Pow. Syst. Res. 80 (2010), 556-561.

[28] ZIEnkiewiCZ, O. C.-EMSON, C.-Bettess, P. : A Novel Boundary Infinite Element, Int. J. Numer. Meth. Eng. 19 (1983), 393-404.

Received 14 December 2011

Jovan Trifunović was born in Belgrade, Serbia, in 1979. He received the Eng degree in electrical engineering and the $\mathrm{MPh}$ degree from the Faculty of Electrical Engineering, University of Belgrade (Serbia) in 2003 and 2009, respectively. He is now a PhD Candidate at the same Faculty, where he has been working as teaching and research assistant since 2005 . His areas of interest currently include grounding systems, low voltage electrical installations and energy efficiency.

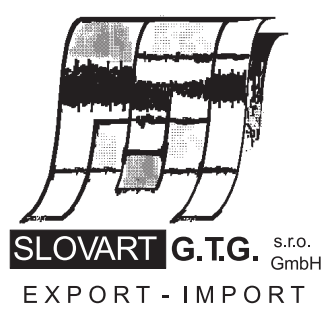

EXPORT - IMPORT
E X P OR T - I M P OR T

of periodicals and of non-periodically printed matters, books and CD-ROMs

Krupinská 4 PO BOX 152, 85299 Bratislava 5, Slovakia tel: ++421 263839 472-3, fax: ++421263839485 info@slovart-gtg.sk; http://www.slovart-gtg.sk

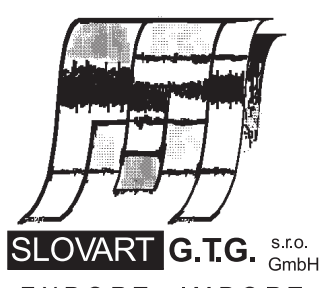

EXPORT - IMPORT 